\title{
Association of the Arginase I with Bronchial Asthma
}

\section{Ashti Mohammad Amin Said ${ }^{\mathrm{a}}$ Ahmed Abdulqader Al-Naqshbandi ${ }^{\mathrm{b}}$ Yasin Kareem Amin ${ }^{c} \quad$ Rebwar Jalal Alid}

\author{
${ }^{a}$ MolecularBiologyDepartment,Medical Research Center /Hawler Medical University.Kurdistan,Iraq. \\ ${ }^{b}$ Bacteriology Department,RizgaryTeaching Hospital/Ministry of Health, Kurdistan,Iraq. \\ ${ }^{c}$ Medical Research Center/Hawler Medical University, Kurdistan, Iraq. \\ ${ }^{d}$ Biochemistry Department, Medical Research Center/Hawler Medical University, Kurdistan,Iraq . \\ kavi1_6@hotmail.com_ahmed79qader@yahoo.com \\ dr_yka@yahoo.com rebwar11@yahoo.com
}

Submission date:- 12/12/2018 Acceptance date:- 20/1/2019 Publication date:- 1/4/2019

Keywords: Arginase I; asthma; L-arginine; L-ornithine; urea.

\begin{abstract}
Objective The aim of this study was to detect the arginase I (ARG I) enzyme in asthma patients, clarify its role, in addition to examining the relationship of this enzyme with bronchial asthma.

Methods:

Blood samples were collected from 100 patients from Department of Medicine in Rizgary Hospital in Erbil City, in addition to intact 100 volunteers; the introduced questionnaire was filled out on the basis of type-induced asthma, duration of the disease, age of the patients, gender, family history, and allergy condition, Serum was separated to perform Enzyme-linked immunosorbent assay (ELISA) in Medical Research Center to examine the association of ARGI with bronchial asthma. By ARG activity we can measure the conversion of arginine to ornithine and urea. By using a quantitative colorimetric assay at $490 \mathrm{~nm}$, employing a QuantiChrom arginase assay kit (Bioassay Systems).

Results: Our results depicted the association between ARGI and bronchial asthma: based on their age, significant elevation of serum arginase level was observed in the patients with $\geq 81$ years old, which mean value $\left(100.16 \pm 19.77^{\mathrm{c}}\right)$, $\mathrm{p}$ value (0.000); also the duration of asthma $\geq 20$ years $\left(82.48 \pm 38.81^{\mathrm{c}}\right), \mathrm{p}$ value $(0.01)$ were remarkably affected; this significance was found in those with types of induced asthma and with allergy condition. But non- significant difference in frequency of abnormal serum arginase level was observed in those patients that have family history of asthma disease and gender of the patients. This finding demonstrated a remarkable association of ARG I in the development of asthma at $p<0.05$.
\end{abstract}

Conclusion: The ELISA results indicated that the ARG I and bronchial asthma are remarkably correlated. Patients with asthmatic symptoms have the high level of ARG I (> $40 \mathrm{IU} / \mathrm{L})$.

\section{1- Introduction}

Asthma is chronic lung disease affects 300 million people worldwide [11. Allergic asthma is a disease of airway inflammation and hyperresponsiveness. Asthma occur by activating $\mathrm{IgE}$, receptor which is bearing mast cells and basophils, and triggering factors for this, is inhalation of allegen when it bind to complementary IgE. And this is lead to lung infiltration by eosinophils, neutrophils, then activated (M2) macrophages and $\left(\mathrm{T}_{\mathrm{H}} 2\right)$ ly mphocytes, which are inflammatory triggers and all these increase mucus production, which is leading to mucosal edema, smooth-muscle hyperresponsiveness, and airway hyperresponsiveness (AHR) due to exposure to e.g. histamine and methacholine [2], [3].

Arginase (ARG) is an essential enzyme that can be detected in mammals and plants. Particularly in humans, being a partaker in the last phase of urine cycle, ARG accelerates conversion of arginine to ornithine and urea. Moreover, ARG level remarkably escalates in those whose body suffers from asthmatic symptoms [4].

The ARG according to Vercelli and Meurs has rule in asthma through different mechanisms which is leading to remodeling of airway through polyamine and proline synthesis by inhibiting nitric oxide, $(\mathrm{NO})$ synthesis, reduction of arginine bioavailability, and increasing ornithine production [5], [6].

Journal of University of Babylon for Pure and Applied Sciences (JUBAS) by University of Babylon is licened under a Creative Commons Attribution 4.0 International License. 2018. 
Cederbaum et al. (2004) showed that the enzyme has two types; ARGI and ARG II [7]. Also, both are, "encoded by a different genes"[8].Furthermore "ARG I may be present inside the cytoplasm and expressed in the liver as a part of the urea cycle. ARG I also present in the airway and lung, which they do not have urea cycle [7], Some studies reported that increase in the level of arginine is an autosomal recessive disease which is caused by a defect in the ARGI enzy me [9].

There is expanding proof that ARG is moreover imperative in the pathophysiology of human asthma [10]. Morris et al (2004). and other researchers reported that decreasing ARG activitv and increasing L-arginine concentrations will occur in some patients which have improvement of asthma symptoms [11].

Moreover, immunohistochemical studies about expanded ARG I protein articulation in the aviation route epithelium and aviation route smooth muscle layer of smoking asthmatics contrasted with nonsmoking patients, which may be initiated by nicotine [12].

With respect to the different opinion about the importance of ARGI in asthma, the aim of this research was to detect ARG I enzyme in asthma patients, clarify its role, in addition to examining the relationship of this enzyme with bronchial asthma.

\section{2- Materials and Methods}

\section{2 -1 Participants}

We performed this study on one hundred subjects with clinical signs of asthma (patients group), and one hundred subjects without clinical signs of asthma (control group), during September 2017 up to May 2018. The ages of the patients ranged from 40-103 years and categorized into three groups: $\leq 60,61-80$, and $\geq 81$.

All work involving human subjects selected from patients attending the Department of Medicine in Rizgary Hospital, in addition to intact volunteers; the introduced questionnaire was filled out on the basis of type-induced asthma, duration of the disease, age of the patients, gender, family history of allergy, and allergy condition, consensually, of course: 79(79\%) out of 100 asthma subjects had an abnormal level of ARGI, and 21(21\%) had a normal level. The ethics approval of this study was given by the Ethics Committee of Medical Research Center /Hawler Medical University.

\section{2-2 Enzyme-linked immunosorbent assay (ELIS A)}

ELISA (ELx800-BioTeK80, U.S.A) in Medical research center was performed for all subjects to examine the association of ARGI with bronchial asthma. Two hundred blood samples were taken from asthma and non-asthma participants. Serum was separated to perform ELISA. By ARG activity, we can measure the conversion of arginine to ornithine and urea, by using a quantitative colorimetric assay at $490 \mathrm{~nm}$, employing a QuantiChrom arginase assay kit (Bioassay Systems). (40 $\mu$ l) of serum sample was combined with $10 \mu \mathrm{l}$ of the substrate buffer, then added to a 96-well flat-bottomed plate with the appropriate blank controls and $50 \mu \mathrm{l} 1 \mathrm{mM}$ Urea reagent (supplied with the kit) then added to wells to stop the reaction of arginase and incubated at RT for two hours. Then measuring the absorbance at $490 \mathrm{~nm}$ and enzy me activity (in IU), calculated according to the kit instructions.

The test result was considered negative (normal value), when the arginase level was $\leq 40$ IU and positive (abnormal level) at $>40 \mathrm{IU}$.

\section{2-3 Statistical Analysis}

Statistical Package for Social Science (SPSS) software version 19 was used for statistical analysis. Qualitative parameters were compared between groups by Pearson Chi-square, while quantitative variables were expressed as the mean \pm standard deviation (SD). Differences were considered statistically significant at $p<0.05$.

\section{4-Results and Discussion}

Study participants were classified into two groups: asthma $(n=100)$ and non-asthma $(n=100)$ subjects. Table (1) depicts the frequencies of normal and abnormal serum ARGs level in healthy and patient groups; in which normal level of control was (100\%), normal level of the patients was (21\%), and the patient abnormal level was (79\%). 
Table 1. The frequency of normal and abnormal serum arginase level in the healthy person and patient groups.

\begin{tabular}{|c|c|c|c|c}
\hline \multicolumn{2}{c|}{} & $\begin{array}{c}\text { Control group } \\
\text { No. 100 }\end{array}$ & $\begin{array}{c}\text { Patient group } \\
\text { No. 100 }\end{array}$ & \multirow{2}{*}{ p. value } \\
\hline \multirow{3}{*}{ Arginase IU/L } & Normal level & $\mathbf{1 0 0 ( 1 0 0 \% )}$ & $\mathbf{2 1 ( 2 1 \% )}$ & \multirow{2}{*}{$\mathbf{0 . 0 0 0}$} \\
\cline { 2 - 4 } & Abnormal level & $0(0 \%)$ & $79(79 \%)$ & \\
\hline
\end{tabular}

According to table (2), the mean age of the study population was $65.73 \pm 15$, the control mean age was $39.9 \pm 10.59$, and the male to female ratio was $7 / 93$. This table summarizes the characteristics of topics by many clinical parameters: significant differences in age, duration of the disease and serum ARG level were observed between control and patient groups. Gender, types of induced asthma, family history and allergy condition were significantly different between groups. Mean value of arginase was $25.93 \pm 7.01$ and $61.28 \pm 33.93$ for healthy donor and asthmatic patients, respectively.

Table 2. Comparison of clinical history between the healthy persons and asthma patients.

\begin{tabular}{|c|c|c|c|c|c|}
\hline & & & $\begin{array}{l}\text { Control group } \\
\text { No. } 100\end{array}$ & $\begin{array}{l}\text { Patient group } \\
\text { No. } 100\end{array}$ & P. value \\
\hline \multicolumn{3}{|c|}{ Age $($ Mean \pm SD) } & $39.9 \pm 10.59$ & $65.73 \pm 15.08$ & 0.041 \\
\hline \multicolumn{3}{|c|}{ Arginase level IU/L (Mean \pm SD) } & $25.93 \pm 7.01$ & $61.28 \pm 33.93$ & 0.000 \\
\hline \multicolumn{3}{|c|}{ Duration year $($ Mean \pm SD $)$} & $0.00 \pm 0.00$ & $10.01 \pm 10.65$ & 0.000 \\
\hline \multirow{2}{*}{\multicolumn{2}{|c|}{ Gender (No.) }} & Male & 60 & 7 & \multirow{2}{*}{0.000} \\
\hline & & Female & 40 & 93 & \\
\hline \multirow{6}{*}{ 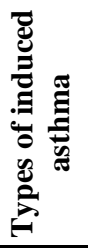 } & \multirow{2}{*}{ Adulthood induced(No.) } & Yes & $\mathbf{0}$ & 98 & \multirow{2}{*}{0.000} \\
\hline & & No & 100 & 2 & \\
\hline & \multirow{2}{*}{ Exercise -induced (No.) } & Yes & $\mathbf{0}$ & 93 & \multirow{2}{*}{0.000} \\
\hline & & No & 100 & 7 & \\
\hline & \multirow{2}{*}{ Occupational induced (No.) } & Yes & $\mathbf{0}$ & 68 & \multirow{2}{*}{0.000} \\
\hline & & No & 100 & 32 & \\
\hline & \multirow{2}{*}{ Family history (No.) } & Yes & $\mathbf{0}$ & 39 & \multirow{2}{*}{0.000} \\
\hline & & No & 100 & 61 & \\
\hline & \multirow{2}{*}{ Allergy (No.) } & Yes & $\mathbf{0}$ & 53 & \multirow{2}{*}{0.000} \\
\hline & & No & 100 & 47 & \\
\hline & 0.05: Significant difference & & & & \\
\hline
\end{tabular}

As table (3) shows, the age of the patients ranged from 40-103years and categorized into three groups: $23 \%$ of asthma patients which have age $\leq 60$ years have a mean of ARG level $53.64 \pm 24.26^{\mathrm{ab}} ; 69 \%$ of asthma patients with 61-80 years old have a mean of ARG level $59.45 \pm 32.46^{\mathrm{b}}$, and; $8 \%$ of them which have $\geq 81$ years old have mean of ARG level $100.16 \pm 19.77^{c}$. Significant elevation of serum ARG level was found in asthma patients with age group $\geq 81$ compared with other groups $(p=0.000)$. Interestingly, in our study, the patients who were $\geq 81$ years showed the highest mean of ARG level (100.16 \pm 19.77$)$, if compared with other group ages. We proposed that the age of patients was related to asthmatic subjects, and can be attributed to increases in ARG I expression and activity. The previous study showed that bronchial asthma is a significant health issue: $5 \%$ to $10 \%$ of people at different ages suffer from such chronic airway disease [14]. 
Table 3. Serum level of arginase in asthma patients according to age groups.

\begin{tabular}{c|c|c|c|c}
\hline & $\begin{array}{c}\leq 60 \\
\text { No. 23 }\end{array}$ & $\begin{array}{c}61-80 \\
\text { No. } 69\end{array}$ & $\begin{array}{c}\geq 81 \\
\text { No. 8 }\end{array}$ & P. value \\
\hline Arginase level IU/L (Mean \pm S D) & $53.64 \pm 24.26^{\text {ab }}$ & $59.45 \pm 32.46^{\mathrm{b}}$ & $100.16 \pm 19.77^{\mathrm{c}}$ & 0.000 \\
\hline
\end{tabular}

Table (4) depicts the duration-based asthma disease. The mean of ARG level was $61.35 \pm 38.15^{\mathrm{ab}}$ for $46 \%$ of patients who were suffering from asthma for 9 years and above. For $38 \%$ of asthma patients who were living with the disease for 10 to 19 years, had the $52.28 \pm 0.53^{\mathrm{b}}$ mean of ARG level. And $16 \%$ of asthma patients with $\geq 20$ disease interval scored $82.48 \pm 38.81^{\mathrm{c}}$. Significant elevation of serum ARG level was observed in patients suffering asthma for more than 20 years $(p=0.01)$. The results revealed that the duration of disease was related to the level of ARG I. Patients with symptoms of asthma ( $\leq 9$ and $\geq 20$ years) have abnormal levels of ARG I, but the highest ARG level $\left(82.48 \pm 38.81^{\mathrm{c}}\right)$ was observed in $16 \%$ of asthma patients who have the disease for more than 20 years. Moreover, the duration of disease is one of the important factors in increasing the activity of ARG I and decreasing L-arginine concentration. In a study done by North et al. It became evident that the increase of ARG I levels in chronic asthma is more significant, compared with acute cases [13].

Table 4. Serum level of arginase in asthma patients according to disease duration.

\begin{tabular}{|c|c|c|c|c|}
\hline & $\begin{array}{c}\leq 9 \text { years } \\
\text { No. } 46\end{array}$ & $\begin{array}{c}10-19 \text { years } \\
\text { No. } 38 \\
\end{array}$ & $\begin{array}{c}\geq 20 \text { years } \\
\text { No. } 16\end{array}$ & P. value \\
\hline Arginase level IU/L (Mean \pm SD) & $61.35 \pm 38.15^{\mathrm{ab}}$ & $52.28 \pm 20.53^{b}$ & $82.48 \pm 38.81^{c}$ & 0.01 \\
\hline \multicolumn{5}{|c|}{ Different letters: mean significant differences, P value $<0.05$ : Significant difference } \\
\hline
\end{tabular}

As table (5) shows, no significant correlation was found between ARGI activity and these variables (gender and family history), except for types of induced asthma and allergy asthma, both which were significant. Based on the results of this study, seventy-eight patients with exercise-induced asthma have high levels of arginase, and fifteen patients have a normal level of the enzyme. According to our knowledge, we could find that exercise-induced asthma was significantly associated with ARG activity. [16] ,in Japan reported that the mean value of ARG activity of eleven employees, who were daily trained for a week, was $6.3 \pm 0.7$. For fifty-three of workers exercised not on a daily basis, the mean value of ARG activity was $4.8 \pm 0.3$. One hundred nineteen workers with no exercise had their mean value of ARG activity touched $3.9 \pm 0.2$. It means that the group with daily training has highest ARG level compared with other groups.

Regarding the study findings, the significant prevalence of abnormal serum ARG level was found in seventy nine patients with adulthood induced asthma, who were recruited for this study at Rizgary Teaching Hospital/Medicine department in Erbil. Morris et al. showed that from twenty-six adult patients that have history of asthma at different stages of exacerbation there is a high ARG activity if compared to normal control subjects without asthma $(1.6 \pm 0.8$ versus $0.5 \pm 0.3 \mu \mathrm{mol} / \mathrm{ml} /$ hour, asthma versus control, $p<0.0001)$ and low level of arginine, compared to normal control subjects without asthma $(45 \pm 22$ versus $94 \pm 29 \mu \mathrm{M}, p<0.0001)\lceil 111$.

In this study, occupations considered one of the causes of asthma: seventy-four patients were workers who inflicted occupational asthma bv breathing in chemical fumes, dust, gases, or other substances on the job, or could result from exposure to a substance which they're sensitive to. The frequency of high level of ARG (which is more than $40 \mathrm{IU} / \mathrm{L})$ found in the seventy-four patients was statistically significant $(p=0.000)$. The previous studies articulated that surrounding particles and ozone layer are the most common causes of urban air pollution, both which are causes of environmental exposures in murine models of airways inflammation due to arginase I up-regulation [17].

The results of our study were strongly related to family history of asthma. Fortv-one patients out of 54 had an abnormal level of ARG, while the rest 13 had normal levels $(P=0.414)$. Our results demonstrated that a family history of asthma is a significant risk factor for asthma and familial risk assessments also help recognizing an individual's highest risk to get asthma. [18]reported that the results of population-based cohort study indicate that the asthma during the first 27 years of life are usually strongly related to family history of asthma. The results indicate that children of asthmatic mother will develop asthma earlier than those with asthmatic father, which is reflected in the effect estimates. Otherwise study of $[19]$ reported that the familiarly asthma both maternal and paternal asthma had more risk of adult -onset asthma. In the present study, fifty-three patients with asthma have allergies , and this is called allergic asthma 
which can be triggered by pet dander, pollen, dust and other allergy stimulators, and forty-seven patients with nonallergic asthma can be spread bv stress. medication. air temperature. smoke, and infections of the airway. It means that asthma can be associated with either an allergic or non-allergic conditions. Forty-nine of fifty-three patients with allergy had an abnormal level of arginase. Consistent with the result of Maarsingh et al. [20]. In this study, we revealed the association of arginase I in the development of asthma.

Table 5. The frequency of clinical history parameters among asthma patients according to the normal and abnormal serum level of arginase.

\begin{tabular}{|c|c|c|c|c|c|}
\hline & & & \multicolumn{2}{|c|}{ Arginase level IU/L } & \multirow{2}{*}{ P. value } \\
\hline & & & $\begin{array}{l}\text { Normal level } \\
\text { No. } 21\end{array}$ & $\begin{array}{l}\text { Abnormal level } \\
\text { No. } 79\end{array}$ & \\
\hline \multirow{2}{*}{\multicolumn{2}{|c|}{ Gender (No.) }} & Male (7) & 1 & 6 & \multirow{2}{*}{0.546} \\
\hline & & Female (93) & 20 & 73 & \\
\hline \multirow{6}{*}{ 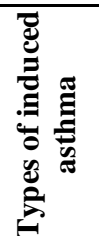 } & \multirow{2}{*}{ Adulthood induced(No.) } & Yes (98) & 19 & 79 & \multirow{2}{*}{0.042} \\
\hline & & No (2) & 2 & $\mathbf{0}$ & \\
\hline & \multirow{2}{*}{ Exercise induced (No.) } & Yes (93) & 15 & 78 & \multirow{2}{*}{0.000} \\
\hline & & No (7) & 6 & 1 & \\
\hline & \multirow{2}{*}{ Occupational induced (No.) } & Yes (68) & 5 & 63 & \multirow{2}{*}{0.000} \\
\hline & & No (32) & 16 & 16 & \\
\hline \multirow{2}{*}{\multicolumn{2}{|c|}{ Family history (No.) }} & Yes (54) & 13 & 41 & \multirow{2}{*}{0.414} \\
\hline & & No (46) & 8 & 38 & \\
\hline \multirow{2}{*}{\multicolumn{2}{|c|}{ Allergy (No.) }} & Yes (53) & 4 & 49 & \multirow{2}{*}{0.000} \\
\hline & & No (47) & 17 & 30 & \\
\hline
\end{tabular}

\section{5-Conclusion}

Our findings provide evidence for the key role of ARG I activity in the asthma disease. Therefore, this enzy me might serve as a useful biological marker in asthma disease.

\section{6-Acknowledgment}

This study has been supported by the Medicine Department in Rizgary Hospital in Erbil

City and Medical Research Center/Hawler Medical University, Kurdistan Iraq.

\section{Conflict of interests}

There are no conflicts of interest.

\section{7- References}

[1] M. Masoli, D. Fabian, S. Holt and R. Beasley, Global Initiative for Asthma(GINA) Program. Global burden of asthma: executive summary of the GINA Dissemination Committee report. Allergy. 59(5):469-78. [PMID: 15080825]. 2004.

[2] J. Bousquet, P.K. Jeffery, W.W. Busse, M. Johnson and A.M. Vignola, Asthma: from bronchoconstriction to airways inflammation and remodeling. Am J Respir Crit Care Med. 161(5):1720-45. [PMID: 10806180]. 2000.

[3] W.W. Busse and R.F. Jr. Lemanske, Asthma. N Engl J Med. 344(5):350-62. [PMID:11172168]. 2001.

[4]H. Chen, B.C.McCaig, M. Melotto, Y.H.Sheng, and G.A.Howe, Regulation of Plant Arginase by Wounding, Jasmonate, and the Phytotoxin Coronatine. J Biol Chem. 279(44):45998-6007. [PMID: 15322128].2004.

[5] D. Vercelli, Arginase: marker, effector or candidate gene for asthma? J Clin Invest. 111(12): 1815-17. [PMID: 12813015]. 2003.

[6] H. Meurs, H. Maarsingh and J. Zaagsma, Arginase and asthma: novel insights into nitric oxide homeostasis and airway hy perresponsiveness. Trends Pharmacol Sci. 24(9): 450-5. [PMID: 12967769]. 2003.

[7] S.D. Cederbaum, H. Yu, W.W. Grody, R.M. Kern, P. Yoo, et al, Arginases I and II: do their functions overlap? Mol Genet Metab. 81 (1): 38-44. [PMID: 15050972]. 2004.

[8] C. Zhang, T.W. Hein, W. Wang, C.I. Chang, and L. Kuo, Constitutive expression of arginase in microvascular endothelial cells counteracts nitric oxide-mediated vasodilatory function. FASEB J. 15(7): 1264-6. [PMID: 11344108]. 2001.

[9] S. Fernando and L. Brendan, Clinical, Biochemical, and Molecular Spectrum of Hyperargininemia Due to Arginase I Deficiency. Am J Med Genet C Semin Med Genet 0(2): 113-20. [PMID: 16602094]. 2006. 
[10] A. Lara, S.B. Khatri, Z. Wang, S.A. Comhair, W. Xu, et al. Alterations of the arginine metabolome in asthma. Am Respir Crit Care Med. 178(7):673-81. [PMID: 18635886]. 2008.

[11] C.R. Morris, M. Poljakovic, L. Lavrisha, L. Machado, F.A. Kuypers, et al. Decreased arginine bioavailability and increased serum. Am Respir Crit Care Med. 170(2):148-53. [PMID: 15070820]. 2004.

[12] C. Bergeron, L.P. Boulet, N. Page, M. Laviolette, N. Zimmermann, et al. Influence of cigarette smoke on the arginine pathway in asthmatic airways: increased expression of arginase I. J Allergy Clin Immunol. 119(2): 391-97. [PMID: 17291856]. 2007.

[13] M.L. North, N. Khanna, P.A. Marsden, H. Grasemann, and J.A. Scott, The functionally important role for argin ase I in the airway hyperresponsiveness of asthma. Am J Physiol Lung Cell Mol Physiol. 296(6): L911-20. [PMID: 19286931]. 2009.

[14] U. Dieter, F. Liat and B.N. William, Bronchial Asthma: Diagnosis and Long-Term Treatment in Adults. Dtsch Arztebl Int. 105(21): 385-94. [PMID: 19626179]. 2008.

[15] S.E. Woods, J. Sorcher and J. King, Young Adults Admitted for Asthma: Does Gender Influence Outcomes? J of Women's Health (Larchmt). 12(5):481-5. [PMID: 12869295]. 2003.

[16] Y. Tsukiyama, T. Ito, K. Nagaoka, E. Eguchi and K. Ogino, Effects of exercise training on nitric oxide, blood pressure, and antioxidant enzymes. J Clin Biochem Nutr. 60(3):180-6. [PMID: 28603344]. 2017.

[17] L. Michelle, A. Hajera, K. Nivedita, U. Bruce, S. Mary, et al. Examining the role of arginase in air pollutioninduced exacerbation of asthma. Allergy Asthma Clin Immunol. 6(Supp13): P5. 2010.

[18] E.M.S. Paaso, M.S. Jaakkola, T.K. Lajunen, T.T. Hugg and J.J.K. Jaakkola, The Importance of Family History in Asthma during the First 27 Years of Life. Am J Respir Crit Care Med. 188(7):624-6. [PMID: 23992594]. 2013.

[19] T.K. Lajunen, J.J.K. Jaakkola and M.S. Jaakkola, Influence of heredity on asthma continues to adulthood. J Allergy Clin Immunol. 131(3):916-8. [PMID: 23246021]. 2013.

[20] H. Maarsingh, B.G.J. Dekkers, A.B. Zuidhof, I.S.T. Bos, M.H. Menzen, et al. Increased arginase activity contributes to airway remodeling in chronic allergic asthma. Eur Respir J. 38(2):318-28. [PMID: 21310883]. 2011.

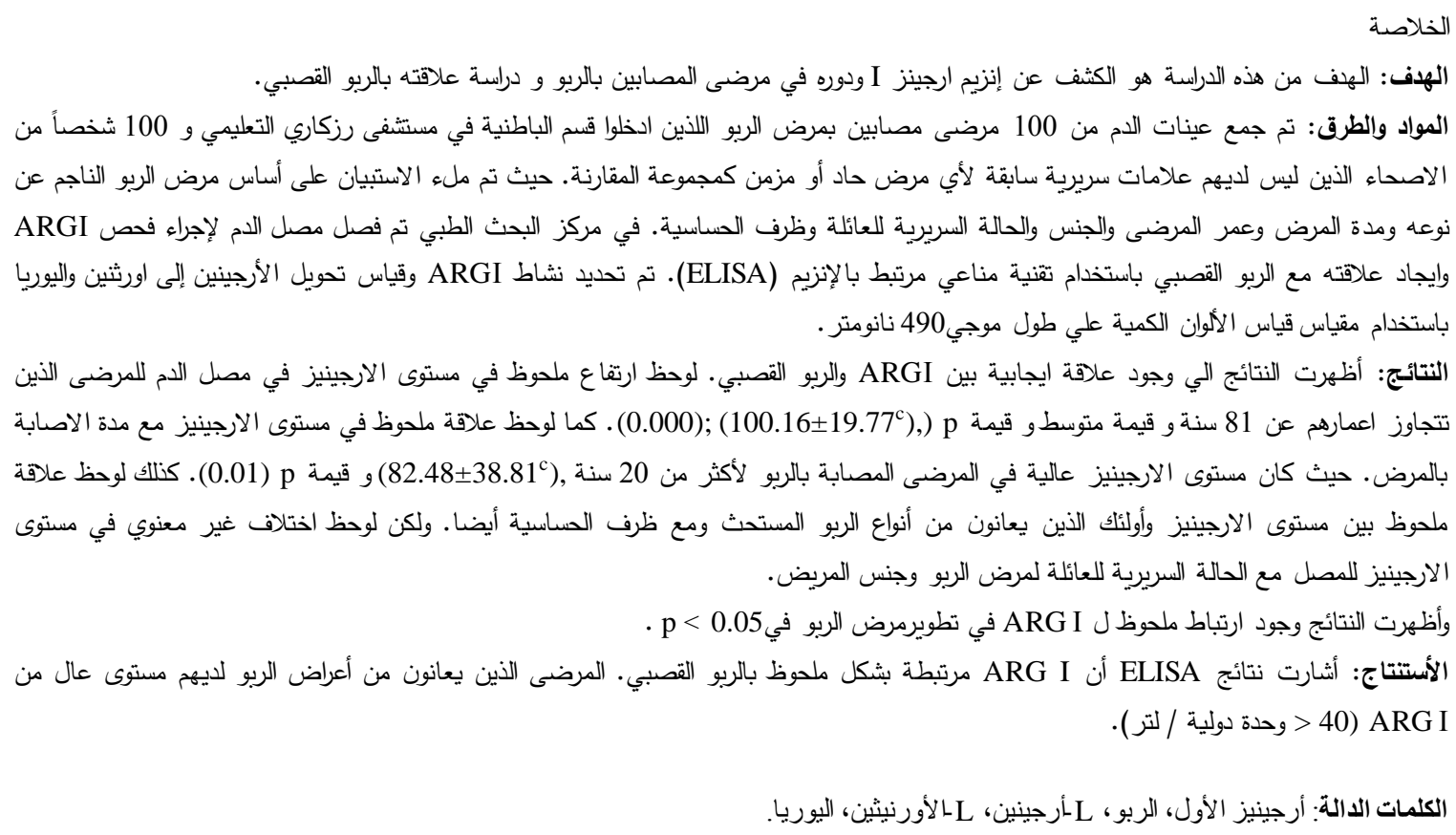

